\title{
ROLE OF MEDICAL THORACOSCOPY IN THE DIAGNOSIS OF PLEURAL EMPYEMA
}

C. Yugandhar Bhatt', Methuku Narender2, Kiran Kumar Kondapaka3, Vavilala Satish Kumar Rao', Auzumeedi Sai Kumar5, Subhakar Kandi ${ }^{6}$

${ }^{1}$ Assistant Professor, Department of Pulmonary Medicine, Deccan College of Medical Sciences, Hyderabad.

${ }^{2}$ Associate Professor, Department of Pulmonary Medicine, Guntur Medical College, Guntur.

3 Post Graduate, Department of Cardiology, SVS, Thirupati.

${ }^{4}$ Assistant Professor, Department of Pulmonary Medicine, Osmania Medical College, Hyderabad.

5 Professor \& HOD, Department of Pulmonary Medicine, Osmania Medical College, Hyderabad.

6 Professor, Department of Pulmonary Medicine, Osmania Medical College, Hyderabad.

\begin{tabular}{l}
\hline ABSTRACT \\
BACKGROUND \\
Medical thoracoscopy is a minimally invasive procedure that allows access to the pleural space using a combination of viewing \\
and working instruments. The main diagnostic and therapeutic indications for Medical Thoracoscopy are difficult pleural effusions, \\
empyemas and pneumothorax. It can also be effectively used in the diagnosis and management of early stages empyema.
\end{tabular}

\section{OBJECTIVE}

To know the role of medical thoracoscopy in the diagnosis of empyema.

\section{METHODOLOGY}

Total number of 20 patients with empyema (Exudative and fibrinopurulent or simple and loculated), who were admitted to Government General and Chest Hospital and Osmania General Hospital between October 2010 to August 2012 were taken in the study.

\section{RESULTS}

Thoracoscopy was performed on 20 patients with empyema. Definitive diagnosis was established in five patients. Of these 20 cases, one had adenocarcinoma, four had granulomatous inflammation of pleura and rest of 15 cases showed nonspecific inflammation of the pleura these cases responded well to antibiotic treatment.

\section{CONCLUSION}

Medical Thoracoscopy is a simple, safe, minimally invasive and less painful procedure efficient diagnostic procedure. It decreases the morbidity and length of hospitalization in loculated empyema.

\section{KEYWORDS}

Carcinoma, Empyema, Loculated, Thoracoscopy, Tuberculosis.

HOW TO CITE THIS ARTICLE: Bhatt CY, Narender M, Kondapaka KK, et al. Role of medical thoracoscopy in the diagnosis of pleural empyema. J. Evolution Med. Dent. Sci. 2016;5(37):2189-2192, DOI: 10.14260/jemds/2016/510

\section{INTRODUCTION}

Medical thoracoscopy is a minimally invasive procedure that allows access to the pleural space using a combination of viewing and working instruments. Jacobaeus is considered the father of thoracoscopic surgery, because he was the first to describe and undertake the procedure of endoscopic exploration of the thorax. It also allows for basic diagnostic and therapeutic procedures to be performed safely.(1) The main diagnostic and therapeutic indications for Medical Thoracoscopy are difficult pleural effusions, empyemas and pneumothorax. In addition, Medical Thoracoscopy provides staging for lung cancer and diffuse malignant mesothelioma. Talc poudrage as the best conservative method for pleurodesis, can also be performed with medical thoracoscopy.

Financial or Other, Competing Interest: None.

Submission 18-03-2016, Peer Review 20-04-2016,

Acceptance 26-04-2016, Published 06-05-2016.

Corresponding Author:

Dr. C. Yugandhar Bhatt,

Assistant Professor,

Department of Pulmonary Medicine,

Deccan College of Medical Sciences,

Hyderabad.

E-mail:drugandhar@gmail.com

DOI: $10.14260 /$ jemds $/ 2016 / 510$
It can also be effectively used in the diagnosis and management of early stages empyema. Medical thoracoscopy is a safe procedure, which is even easier to learn than flexible bronchoscopy.

\section{AIM OF THE STUDY}

To know the role of medical thoracoscopy in the diagnosis of pleural empyema.

\section{MATERIALS AND METHODS}

Total number of 20 patients with empyema (Exudative and fibrinopurulent or simple and loculated), who were admitted to Government General and Chest Hospital and Osmania General Hospital between October 2010 to August 2012 were taken in the study.

\section{Study Design}

Prospective observational study.

\section{Inclusion Criteria}

All empyema patients who need ICD insertion.

\section{Exclusion Criteria}

1. Organized empyema.

2. Bleeding diathesis or anti-coagulation. 
3. Occluded pleural cavity.

4. Refractory cough.

5. Acute coronary syndrome or uncontrolled cardiac arrhythmias.

6. Hemodynamic instability.

7. Respiratory failure.

8. Unable to obtain informed consent.

9. Less than 20 years of age and more than 60 years.

10. Uncontrolled Diabetes or Hypertension.

11. Patients with COPD with acute exacerbation.

\section{Ethical Issues}

The study has the approval of the Institutional ethical committee of Government General and Chest Hospital and Osmania General Hospital.

\section{Pre Thoracoscopic Evaluation}

When thoracoscopy procedure is being performed electively the patients typically have to undergo routine prethoracoscopic evaluation. As a routinely, we performed chest radiograph, ultrasonography (USG) of chest and abdomen, frequently supplemented with computerized tomography (CT) scan of Chest in assessing the hemi thorax of interest. USG Chest and CT chest provides basis of determining the point of inserting of the thoracoscopy. Respiratory status is being evaluated with arterial blood gas analysis and spirometry. Complete blood picture with ESR and coagulation parameters, and ECG and 2D Echo were done.

The preanaesthetic check-up is routinely done by anaesthesiologist, and he interviews the patients and evaluate the patients' health status, during which he or she may advice the additional diagnostic or laboratory tests such as Blood grouping and typing and serum electrolytes etc. Anaesthesia care provider discusses the procedure from an anaesthesia perspective and then obtains well informed written consent for anaesthesia from the patient.

\section{Procedure}

Single port technique with Karlstorz Thoracoscope, was used for thoracoscopy. Patient was placed in the lateral decubitus position with the healthy lung down. The arm on the side of the exploration is positioned above the patients head in order to widen the intercostal space.

After local anaesthesia with 2\% lidocaine and sedation with midazolam drip, a small $14 \mathrm{~F}$ caliber trocar was introduced in the intercostal space $\left(5^{\text {th }} / 6^{\text {th }}\right)$ after incising the chest wall. The suction catheter was introduced through the cannula, and pus is drained, allowing air to enter into the pleural cavity. After careful visualization of entire pleural cavity with thoracoscope, multiple biopsy bits were taken at multiple sites. In case of multiple loculations, the loculations was broken down to make a single pleural cavity. Anaesthesia care provider frequently monitored the patients i.e. cardiac monitoring with multi-channel ECG, $\mathrm{O}_{2}$ saturation with pulse oximeter. Haemostasis was secured and intercostal chest drainage tube kept.

\section{Postoperative Care}

After the thoracoscopy was completed, the patient was shifted to post anaesthesia care unit (PACU). The patient was monitored by the anaesthesia care provider and circulating nurse in PACU.
The PACU nurse observed the patient for physiological stability by monitoring and documenting vital signs, and the patient's pain level. The PACU doctor frequently examine the patient. PACU nurse checked the incision site and chest drain for bleeding or oozing. The patients were shifted to routine ward after 6 hours of careful observation. Patients were advised chest X-ray (CXR) PA view immediately next day. Extubating of intercostal chest drainage tube (ICDT) was done after full expansion of the lung and the drain $<50 \mathrm{ml}$ per day. On an average patient was discharged after 8 days of procedure.

\section{RESULTS}

Thoracoscopy was performed on 20 patients with pleural empyema. Median age of patients is 35 years (Range 21 to 57 years), 15 (75\%) males and 5 (25\%) females. Thoracoscopy guided pleural biopsy was done at multiple sites (4- 6 bits) and the samples were subjected for histopathological examination and culture for Mycobacterium tuberculosis and pyogenic culture and drug sensitivity. Definitive diagnosis was established in five patients. None of the biopsy specimens showed any bacterial or tuberculosis culture positive.

Of these 20 cases, one had adenocarcinoma, four had granulomatous inflammation of pleura and rest of 15 cases showed nonspecific inflammation of the pleura. In the patient with adenocarcinoma, we are not suspicious of malignancy either clinically or radiologically, it was surprise to us to receive adenocarcinoma report. The ICDT was removed after 5 to 7 days. In one case (5\%), the procedure was converted into the thoracotomy, because of poor visibility and dense adhesions of the pleura. The procedure completed with the help of Cardio-Thoracic surgeon. The mean length of post procedural hospital stay is 8 days.

\section{Complications}

The complications observed in our study are negligible. One patient had acute abdominal pain on first post-operative day, which was relieved with conservative management. None of the patients had complications of subcutaneous emphysema, haemorrhage, arrhythmias. All patients complained of pain at site of ICDT which was relieved with analgesics. Fever was observed in 8 patients (40\%), which was subsided with antipyretics for 24 to 48 hours.

\section{Statistical Analysis}

As the sample size of our study is small and is an observational study. Hence statistical analysis not done.

\begin{tabular}{|c|c|c|c|}
\hline \multirow{2}{*}{$\begin{array}{c}\text { Age } \\
\text { Distribution } \\
\text { Age in years }\end{array}$} & Total & Sex Distribution \\
\cline { 3 - 4 } & & $\mathbf{M}$ & $\mathbf{F}$ \\
\hline $21-45$ & 17 & 12 & 5 \\
\hline $46-57$ & 3 & 3 & 0 \\
\hline \multicolumn{3}{|c|}{ Table 1: Age and Sex Distribution } \\
\hline
\end{tabular}

\begin{tabular}{|c|c|c|}
\hline \multicolumn{1}{|c|}{ Type } & $\begin{array}{c}\text { Total } \\
\text { No. }\end{array}$ & $\begin{array}{c}\text { Prevalence } \\
\text { (\%) }\end{array}$ \\
\hline A. $\quad$ Adenocarcinoma & 1 & 5 \\
\hline B. $\begin{array}{l}\text { Granulomatous } \\
\text { Inflammation }\end{array}$ & 4 & 20 \\
\hline C. $\begin{array}{l}\text { Nonspecific Inflammation } \\
\text { of Pleura }\end{array}$ & 15 & 75 \\
\hline \multicolumn{2}{|c|}{ Table 2: Histopathologic Diagnosis of Pleural Biopsy } \\
\hline
\end{tabular}




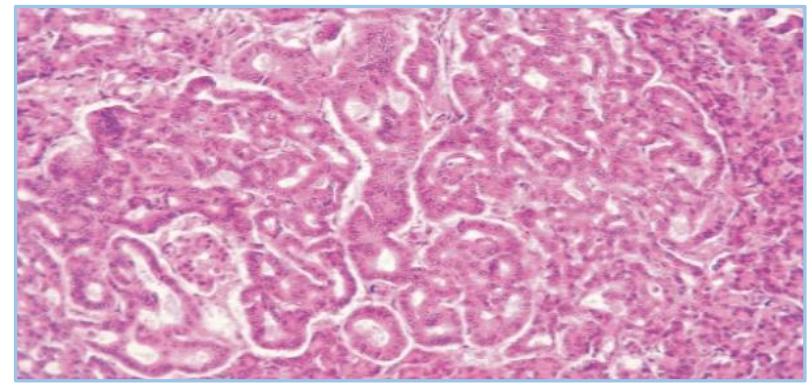

Fig. 1: Adenocarcinoma

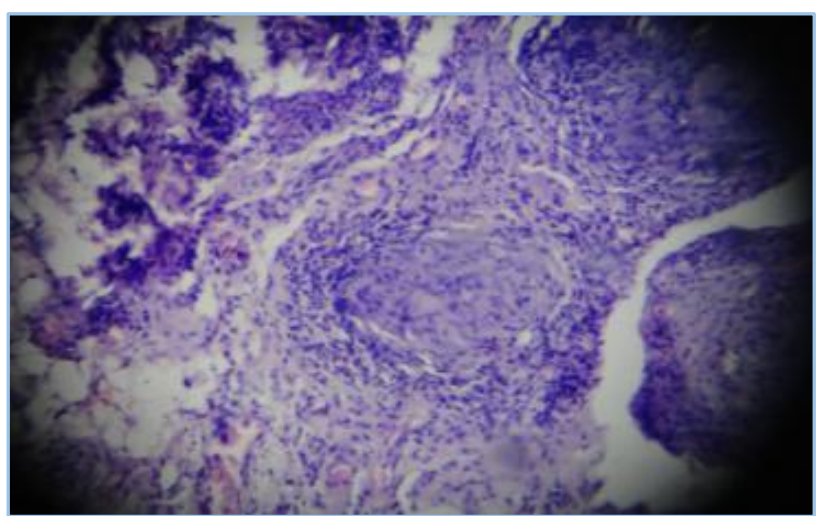

Fig. 2: Granulomatous Inflammation of the Pleura

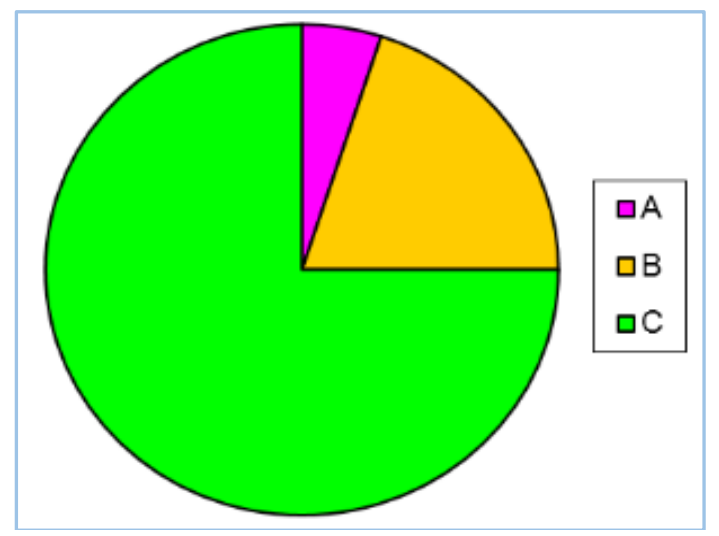

\section{Fig. 3: The Pie Diagram showing Histopathological} Result of Pleural biopsy in Empyemas

\section{DISCUSSION}

Empyema thoracis remains a significant cause of morbidity and even mortality, in modern thoracic practice. A Para pneumonic effusion will develop in up to $57 \%$ of patients hospitalized with bacterial pneumonia.(2) Purulent empyema thoracis will develop in up to $20 \%$.(3) The diagnosis and management of thoracic empyema is often challenging, if it progresses to the fibro purulent or organized phases, with simple antibiotic and drainage. Surgical decortication usually becomes necessary.(4) The development of thoracoscopy has changed the approach to thoracic empyema.(5) Although thoracoscopy has proved useful in the treatment of infected pleural space, in particular in multiloculated empyema, where it allows recovery avoiding thoracotomy, even today its employment has not been justified by large controlled trials.(6,7) Moreover there are no prospective, controlled studies on the role of medical thoracoscopy in Para pneumonic effusions and empyemas.
In G.F. TASSI ET AL, they concluded that, medical thoracoscopy as a draining procedure intermediate between tube thoracotomy and thoracoscopic surgery.(8) It is essential that it is performed early in the course of empyema and it is particularly advisable for frail patients at high surgical risk.

Thoracoscopic examination yields better anatomical information about the stage and extent of the empyema, and guides us about the management plans. Debridement of the loculations and fibrinous debris in the pleural cavity allows us to re-establish the single pleural cavity, and chest tube placement under vision, in addition to the pleural biopsy for histopathological and microbiological examination. This procedure can be described as an excessive debridement (Not a Decortications), unless the parietal and visceral pleura removed completely.(5,8) Thoracoscopy came into wide spread use beginning in the early 1990's.

In India still it is not being used commonly, probably due to lack of familiarity with the instrument and experience in its usage. In our study, we subjected both simple and loculated empyemas, for medical thoracoscopy. In multiloculated empyemas, apart from pleural biopsy, we broken down the loculations and made it into a single pleural cavity, to ensure proper drainage of empyema. But in one patient (5\%) it was converted to thoracotomy, because of poor visibility of pleural space and dense adhesions of the pleura. In Muharrem Celik et al, they performed 459 videoassisted thoracoscopic procedures, the overall conversion to thoracotomy was $12.6 \%$.(9) The advantage of thoracoscopy over open surgical procedure is avoidance of surgical risk, general anaesthesia, muscle division and bone fractures that allows for diminished duration and intensity of pain and a shorten time to return to full activity. This study was undertaken to evaluate the diagnostic yield of thoracoscopy at our institution.

In our study out of 20 patients with empyema, a definite diagnosis was established in five patients using thoracoscopy, with diagnostic yield of $25 \%$. In Muharrem Celik et al.(9) the success rate of nontuberculous thoracic empyema was $87.3 \%$. Although the diagnostic yield is low, in addition to the pathological diagnosis, thoracoscopy reduced the morbidity in multiloculated empyemas by adhesiolysis. All cases showed good lung expansion. In P.D. Ridley et al, they conducted thoracoscopic debridement and pleural irrigation in empyema, showed complete resolution in $60 \%$ of cases.(10) of these 20 cases, one had adenocarcinoma, four had granulomatous inflammation of pleura and rest of 15 cases showed nonspecific inflammation of the pleura these patients responded well to antibiotics and discharged. In the patient with adenocarcinoma, we are not suspicious of malignancy either clinically or radiologically, it was surprise to us to receive adenocarcinoma report. The ICDT was removed after 5 to 7 days.

In Paolo Claudio Cassina et al, they conducted videoassisted thoracoscopy in pleural empyema, the mean chest tube drainage was 7.1 days (4-140 days).(11) In Kent W. Kercher et al, they conducted thoracoscopic decortications in children, the average chest tube drainage was 12.3 days.(12) The average duration of post procedure hospital stay 7 to 9 days. In Philip Hornik et al, they conducted Videothoracoscopy in the treatment of early empyema, the mean post-operative stay was 7.8 days.(13) 
Overall the complications of thoracoscopy appears to be less, and it is very safe. No mortality was observed in the present study. According to Martin $\mathrm{H}$ et al, patients with multiloculated empyema, who was stratified by ultrasonography and treated with medical thoracoscopy shows that this approach is safe, minimally invasive and efficient in empyema patients.(14) In the study by Viskum K, Enk B., and Colt HG mortality rate associated with thoracoscopy ranges from 0.01 to $0.24 \% .(15,16)$

\section{CONCLUSION}

Medical Thoracoscopy is a simple, safe, minimally invasive and less painful procedure efficient diagnostic procedure. It decreases the morbidity and length of hospitalization in loculated empyema.

\section{REFERENCES}

1. Armin Ernst, Gerard A Silvestri, David Johnstone. Interventional pulmonary procedures: guidelines from ACCP. Chest 2003;123:1693-1717.

2. Lim WS, Lewis S, Macfarlane JT. Severity prediction rules in community acquired pneumonia: a validation study. Thorax 2000;55(3):219-23.

3. Sahn SA. Management of complicated parapneumonic effusion. Am Rev Respir Dis 1993;148(3):813-7.

4. Colice GL, Curtis A, Deslauriers J, et al. Medical and surgical treatment of parapneumonic effusions: an evidence-based guideline. Chest 2000;118(4):1158-71.

5. Sendt W, Foster E, Hau T. Early thoracoscopic debridement and drainage as definite treatment for pleural empyema. Eur J Surg 1995;161(2):73-76.

6. Silen ML, Naunheim KS. Thoracoscopic approach to the management of empyema thoracis. Indications and results. Chest Surg Clin N Am 1996;6(3):491-499.
7. Waller DA. Thoracoscopy in management of postpneumonic pleural infections. Curr Opin Pulm Med 2002;8(4):323-326.

8. Tassi GF, Davies RJ, Noppen M. Advanced techniques in medical thoracoscopy. Eur Respir J 2006;28(5):10511059.

9. Muharrem Celik, Semih Halezeroglu, Canon Senol, et al. Video-assisted thoracoscopic surgery: experience with 341 cases. European journal of Cardio-thoracic Surgery 1998;14(2):113-116.

10. Ridley PD, Braimbridge MV, et al. Thoracoscopic debridement and pleural irrigation in the management of empyema thoracis. Ann Thorac Surg 1991;51(3):4614.

11. Paolo Claudio Cassina, Markus Hauser, Ludger Hillejan, et al. Video-assisted thoracoscopy in the treatment of pleural empyema: stage-based management and outcome. J Thorac Cardiovasc Surg 1999;117(2):234-8.

12. Kent W Kercher, Robert J Attorri, J David Hoover, et al. Thoracoscopic decortication as first-line therapy for paediatric parapneumonic empyema. Chest 2000;118(1):24-27.

13. Philip Hornik, Edward R Townsend, David Clark, et al. Videothoracoscopy in the treatment of early empyema: an initial experience. Ann $\mathrm{R}$ Coll Surg Engi 1996;78(1):45-48.

14. Martin H Brutsche, Gian-Franco Tassi, Sandor gyorik, et al. Treatment of sonograohically stratified multiloculated thoracic empyema by medical thoracoscopy. Chest 2005;128(5):3303-3309.

15. Viskum K, Enk B. Complications of thoracoscopy. Poumon Coeur 1981;37(1):25-2.

16. Colt HG. Thoracoscopy: window to the pleural space. Chest 1999;116(5):1409-1415. 